\title{
Lei de Responsabilidade Educacional no Brasil (2006-2015): das promessas de qualidade da educação às incertezas
}

\section{Educational Responsibility Law in Brazil (2006-2015): from the education quality promises to uncertainties \\ Ley de Responsabilidad Educativa en Brasil (2006-2015): de las promesas de calidad de la educación a las incertidumbres \\ ALLAN SOLANO SOUZA ANTÔNIO CABRAL NETO}

Resumo: Este artigo objetiva analisar o percurso da construção da Lei de Responsabilidade Educacional (LRE) no Brasil, com base em um mapeamento dos projetos de leis disponíveis no portal eletrônico da Câmara dos Deputados. Para o corpus da pesquisa, foram utilizados, como procedimentos, a revisão de literatura e a análise documental, que delineiam as bases da proposta de política de responsabilidade educacional. Como resultado, é possível destacar que, subjacente a essa lógica, existe, majoritariamente, uma concepção de responsabilização como sinônimo de "culpabilização" dos gestores públicos pelos resultados educacionais.

Palavras-chave: Lei de responsabilidade educacional. Responsabilização. Controle de resultados.

\begin{abstract}
This article aims to analyze the course of the construction of the Educational Responsibility Law (LRE) in Brazil, based on a mapping of the draft laws available on the electronic portal of the Chamber of Deputies. In the corpus of the research, were used, as procedures, the literature review, and the documental analysis that delineate the bases of the educational responsibility policy proposal. As a result, it is possible to underline that, behind this logic, there is, mostly, a conception of accountability as a synonymous of "scapegoating" of the public managers by the educational outcomes.
\end{abstract}

Keywords: Educational Responsibility Law; accountability; control of results.

Resumen: Este artículo tiene como objetivo analizar el recorrido de la construcción de la Ley de Responsabilidad Educativa (LRE) en Brasil, con base en un mapeamiento de los proyectos de leyes disponibles en el portal electrónico de la Cámara de Diputados. Para el corpus de la investigación, fueran utilizados como procedimientos la revisión de literatura y el análisis documental que delinean las bases de la propuesta de política de responsabilidad educativa. Como resultado, es posible destacar que, subyacente a esa lógica, existe, mayoritariamente, una concepción de responsabilidad como sinónimo de "culpabilidad" de los gestores públicos por los resultados educacionales.

Palabras clave: Ley de responsabilidad educativa. Responsabilidad. Control de resultados. 


\section{INTRODUÇÃO}

No Brasil, não está aprovada, ainda, uma lei de responsabilidade educacional; entretanto, desde 2006, tramita na Câmara dos Deputados um projeto de lei (PL 7.420/2006) com a finalidade de responsabilizar os gestores públicos pela qualidade de ensino ofertado pelos sistemas educacionais mediante os resultados anuais das avaliações internas e externas. Trata-se de uma proposição original da Deputada Raquel Teixeira, pertencente aos quadros do Partido da Social Democracia Brasileira (PSDB) do Estado de Goiás. O processo de produção dessa lei tem provocado uma pluralidade de leituras entre os deputados que, ora relaciona a responsabilidade com o uso dos recursos públicos da educação, ou com a definição de padrões de qualidade das escolas a serem alcançados, ora com a aplicação de punições com base nos resultados, mediante aplicação de sanções administrativas e jurídicas.

Embora essa discussão tenha antecedido a aprovação do Plano Nacional de Educação (PNE 2014-2024), eu trânsito se intensifica, na Câmara dos Deputados, no mesmo período de debates sobre a sua elaboração, atribuindolhe maior visibilidade. Nesse sentido, o Plano Nacional de Educação 2014-2024 estabeleceu o prazo de um ano para a aprovação de uma Lei de Responsabilidade Educacional que, segundo Ximenes (2012), representa um marco importante na trajetória do direito à qualidade da educação, realçando, todavia, a necessidade de uma reflexão mais acurada a respeito de suas intenções no campo educacional.

Este artigo objetiva analisar o percurso da construção da Lei de Responsabilidade Educacional (LRE) no Brasil, com base em um breve mapeamento dos projetos de leis que transitam na Câmara dos Deputados desde 2006 até 2015.

Como procedimento de pesquisa, adotaram-se a revisão bibliográfica e a análise documental. Entre os documentos, destacam-se dois relatórios: um, produzido pela Comissão Especial de Educação, criada para debater sobre diferentes concepções de responsabilidade educacional; o outro, produzido na Comissão de Finanças da Câmara dos Deputados, verificando a viabilidade financeira para implementação da LRE. Além desses relatórios, foram considerados os projetos de leis de responsabilidade educacional, disponíveis no sítio da Câmara dos Deputados, assim como matérias de jornais de circulação nacional. Para essa composição, ainda foram considerados vídeos de audiências públicas sobre essa matéria no âmbito da Comissão Especial de Educação, designada para debater e apresentar uma proposta de LRE e, ainda, uma entrevista da Deputada Raquel Teixeira concedida ao Programa Opinião da TV Assembleia de Goiás. Outros documentos subsidiaram nossa análise, tais como: o documento-base da 
Conferência Nacional de Educação (Conae), realizada em 2010, e o documentoreferência que norteou a Conae 2014. A primeira precedeu a subscrição da Lei $n^{\circ}$ 13.005/2014 (BRASIL, 2014), do Plano Nacional de Educação (PNE, 2014-2024) e a segunda ocorreu após a aprovação desse PNE. Assim como um documento produzido pela Secretaria de Articulação com os Sistemas de Ensino, em que expõe sua posição sobre diversas ações da secretaria, inclusive, no tocante à lei de responsabilidade educacional. Finalmente, um documento produzido pelo Fórum Nacional de Educação sobre a LRE.

O tratamento atribuído a esses dados considerou alguns passos da análise de conteúdo (BARDIN, 1977), tais como: a leitura flutuante, construção de unidades de registro e, finalmente, a inferência com base na literatura especializada e em documentos produzidos no período de 2006 a 2015.

Este artigo está organizado em três seções. Na primeira, aborda-se o contexto de produção e discussão do projeto de LRE; já a segunda discute o tema da responsabilidade educacional no âmbito das conferências nacionais de educação e do PNE (2014-2024) (BRASIL, 2014); a terceira registra o trânsito, de 2006 a 2015, dos projetos de LRE na Câmara dos Deputados.

\section{O CONTEXTO DE PRODUÇÃO E DISCUSSÃO DO PROJETO DE LEI DE RESPONSABILIDADE EDUCACIONAL}

A discussão e a produção do projeto de Lei de Responsabilidade Educacional (LRE) no Brasil estão situadas no contexto da Nova Gestão Pública e da globalização neoliberal, referenciadas na lógica do setor privado como estratégia para resolver os problemas de eficiência do setor público, em que, na ótica gerencial, a perspectiva de mercado contribui para responder, positivamente, às crises de um modelo tradicional.

Nesse contexto, a preocupação com a proposição de uma LRE no Brasil, por um lado, é decorrente dos embates em torno dos problemas de qualidade na educação diagnosticados pelos exames nacionais e internacionais, que atestaram resultados pífios com base na divulgação das avaliações; por outro, vem sendo conduzido por reformadores empresariais ${ }^{1}$ interessados pelos assuntos da educação, tendo, como referência, os princípios do gerencialismo.

\footnotetext{
1 Com base em Freitas (2012), o termo reformadores empresariais (Corporate Reformers) da educação foi cunhado por Diane Ravitch, que atuou na gestão da educação americana, refletindo uma coalizão de ideias entre políticos, mídia, empresários, empresas educacionais, institutos e fundações privadas, que entendem possuir a iniciativa privada uma forma mais adequada para consertar a organização da educação.
} 
Com o intuito de compreender a natureza do processo de concepção de uma LRE brasileira, verificou-se por meio de consulta ao sítio da Câmara dos Deputados que sua oficialização, nessa Casa Legislativa, foi registrada em 2006, quando a Deputada Raquel Teixeira (PSDB) apresentou o Projeto de Lei $n^{\circ}$ 7.420/2006 (BRASIL, 2013b), cujo teor estabelece referenciais para a garantia de padrão de qualidade na Educação Básica e define a responsabilidade dos gestores públicos nesses termos.

As motivações quanto à concepção da LRE foram apresentadas pela deputada a partir de uma entrevista ao Programa Opinião da TV Assembleia de Goiás $^{2}$ (SINTEGO, 2013). Para a autora do projeto, a sua primeira motivação deveu-se à identificação da distância que havia entre o discurso e a prática dos governantes, que precisavam se aproximar, ressaltando que, em educação, havia muita discussão e pouca determinação de prioridades. Assim, se posicionou:

\begin{abstract}
Às vezes eu tenho a impressão que nós da educação ficamos na discussão, achando que estamos discutindo, mas na hora da prioridade mesmo, no mundo capitalista a prioridade é definida por orçamento por uma série de coisas e quando você vai olhar isso você vê que não é bem assim. Então, eu queria que a gente tivesse também algum mecanismo de garantir educação de qualidade para os alunos [...]. Eu me perguntava o seguinte, quem é que vai garantir o direito do aluno de aprender, e eu acho que é a legislação, é o estado brasileiro que tem que garantir esse direito das crianças de aprender. Queria que a gente tivesse o triângulo meio virtuoso do sistema transparente, do controle social (SINTEGO, 2013).
\end{abstract}

Nesse trecho da entrevista, a Deputada deixou claro que havia a necessidade de determinar os responsáveis pela garantia do direito à aprendizagem do aluno, na medida em que os professores possuem sindicatos para defender os direitos dos professores. Ao retomar acerca das suas motivações, afirma:

Claro que essa não é uma lei que vai ter o amor incondicional de gestores. A gente sabe que vai ter muita reação, de governadores, de prefeitos. Eu hoje entendo que isso é real. É uma lei que vai ter essa resistência. Acho que talvez o grande desafio para redigir uma lei moderna atual, seja definir um pouco o que é que é qualidade. Então o que é a qualidade da educação? São os insumos? É o processo? São as metas? Quando eu coloco insumos, eu estou colocando infraestrutura, carreira, [...]; tudo isso que é absolutamente essencial, que é a carreira, que é a valorização, que é a infraestrutura da escola, que são as condições tecnológicas. Insumos, metas, porque a gente não avalia somente pelo IDEB, é um indicador importante, mas ele não mostra tudo que está acontecendo dentro do processo educacional. [...] (SINTEGO, 2013). 
Nesse trecho da entrevista, a Deputada Raquel Teixeira deixa claro que se trata de uma proposição que não agrada diretamente a governadores, prefeitos, haja vista que a reação resistente dos administradores públicos é uma constante. Acredita, porém, que o maior desafio para esse projeto é a definição do conceito de qualidade. Analisando a ótica da referida parlamentar, é possível perceber que, na prática, sua preocupação está voltada, principalmente, para a definição de metas e indicadores de qualidade, denotando, portanto, uma visão de qualidade mais próxima do aumento de controle de resultados. Na ótica da NGP, essa política de metas e indicadores tem como objetivo oferecer elementos de "informação e intervenção aos responsáveis pela administração pública, contribuir para a melhoria da capacidade de prestar contas das organizações públicas, ajudar na alocação de objetivos e responsabilidades e possibilitar a avaliação de desempenho dos gestores públicos" (ARAÚJO, 2010, p. 231).

A continuidade do discurso da Deputada Raquel Teixeira revela que há uma forte preocupação com a definição de mecanismos de controle e acompanhamentos das metas, marcando, mais uma vez a presença da NGP, quando, finalmente, assinala:

A gente tem que ter mecanismos de acompanhamento, e se as essa meta não foi atingida num determinado município, num determinado estado, o gestor vai ter que explicar o que aconteceu no período: não houve escolas em número suficiente? Não contratou professores em número suficiente? Ninguém está falando da palavra punição, penalidade, mas tem que ter consequência, responsabilização. [...] O gestor pode ficar inelegível nos próximos quatro anos, sei lá. Alguém tem que responder por isso. Por isso que eu disse, quem vai garantir o direito das crianças? (SINTEGO, 2013).

A preocupação da Deputada Raquel Teixeira reside na necessidade de definição de formas de punição aos gestores públicos que não propiciam as condições para a efetivação do direito à educação. Desse modo, exemplifica que a sua inelegibilidade seria uma saída, podendo existir outras.

Em síntese, a Deputada Raquel Teixeira demonstra a necessidade de chamar o gestor público para responder pelo direito à aprendizagem do aluno quando ele não está sendo garantido. As ideias formuladas pela deputada trazem elementos que propiciam um debate crítico em torno da responsabilidade pelo direito à aprendizagem, porém não suficiente para compreender os desafios reais da escola pública brasileira, tais como: formação inicial e continuada de professores, em nível superior (graduação e pós-graduação); democratização da gestão dos sistemas e das escolas; avaliações que considerem as condições objetivas (salários melhores, infraestrutura, recursos materiais, incluindo, os recursos financeiros, e humanos) e subjetivas (cultura organizacional, clima escolar, diversidade). Não 
é producente centrar o foco exclusivo na busca de encontrar os culpados pelos pífios resultados da aprendizagem dos alunos, se as escolas continuam a enfrentar problemas estruturais e infraestruturais para o seu funcionamento.

A posição assumida pela deputada no que concerne à concepção de uma LRE no Brasil está vinculada a uma perspectiva de qualidade e de responsabilização dos atores escolares e dos gestores públicos que seja capaz de maximizar o controle do acesso, do financiamento e a definição de padrões mínimos de qualidade. Conforme observado em seu discurso, as palavras "consequência" e "responsabilização" são utilizadas para sublinhar a possibilidade de aplicar penalidades e punições. E esse é um dos rumos que têm sido tomados pelo debate sobre a responsabilização educacional: a punição de gestores, seja pela perda de mandatos, seja pelo travamento ou restrições no recebimento de recursos financeiros.

Ademais, essa perspectiva de qualidade é controversa, pois, de acordo com Oliveira e Araújo (2005), persiste o desafio de definição de padrões mínimos. Assim,

O aumento de recursos ou a definição de insumos são condições necessárias mas insuficientes, por si mesmas, para gerar qualidade, visto que existe uma série de variáveis que compensam o efeito negativo das adversas condições socioeconômicas e culturais, contribuindo para que os alunos possam alcançar bons resultados ( $p$. 20).

Para esses autores, a definição de insumos torna-se necessária, mas, isoladamente, esses insumos não determinam os parâmetros, pois a articulação entre padrões de qualidade e as políticas de financiamento e avaliação da educação podem ser um primeiro passo, garantidas as mesmas condições objetivas aos sistemas, visando à redução até alcançar a eliminação das desigualdades e assimetrias que caracterizam o federalismo brasileiro.

O PL da responsabilidade educacional $n^{0} 7.420 / 2006$ (BRASIL, 2007) recebeu, inicialmente, voto favorável da Comissão Especial ${ }^{3}$ da Câmara dos Deputados, e, posteriormente, da Comissão de Educação e Cultura, em reunião Ordinária deliberativa realizada no dia 2 de maio de 2007, cujo relatório foi apresentado pelo Relator-Substituto Deputado Gilmar Machado, que acatou o parecer da Relatora Deputada Fátima Bezerra (PT). Conforme esse relatório, até aquele momento (2007), não havia recebido, no prazo regimental, nenhuma emenda. Vale ressaltar que as emendas só começaram a ser apresentadas alguns anos mais tarde, conforme será visto adiante. 
Verificou-se que o voto dos relatores se deu com base na exposição dos resultados críticos da educação brasileira, do período que marca a passagem da metade da década de 1990 para o início dos anos 2000, tendo, como uma de suas referências, a publicação dos dados do Programm International Student Assessment (Pisa), que consiste em uma avaliação internacional dos países membros da OCDE. No relatório da comissão, ficou explícita a necessidade de chamar os agentes públicos para responder acerca dos frágeis resultados educacionais do Brasil.

Do ponto de vista do desempenho dos alunos em avaliações internacionais, o relatório destaca que

O desempenho de nossos estudantes em exames internacionais, como o PISA, é precário e temos ocupado, como todos sabem, sistematicamente os últimos lugares nessa avaliação. Esse resultado, porém, está coerente com o atraso escolar e a baixa qualidade presente no sistema de educação básica do nosso país e corrobora os dados acima citados (BRASIL, Comissão de Educação e Cultura, 2007, p. 2-3).

Os dados constantes no relatório da Comissão Especial para debater o PL no 7.420/2006 (BRASIL, 2007) permitem uma reflexão importante quanto à produção dos números estatísticos; eles não devem ser considerados isoladamente, mas alinhados à presença de um quadro de desmotivação, frustração, e ausência de compreensão da comunidade escolar acerca do ensino ofertado nas escolas públicas. Destaca o relatório:

Esse conjunto de coisas gera prejuízos de toda ordem. Aos alunos, que se veem desestimulados com a insensatez de estudar e não aprender. Aos professores, frustrados com os resultados pífios de seu trabalho. Aos pais, que, desorientados, não compreendem o porquê do Estado oferecer uma escola que não motiva e, pior, não se traduz no futuro melhor que esperam para os filhos. À sociedade, que vê serem desperdiçados os recursos arrecadados em forma de impostos (BRASIL, 2007, p. 3).

Em inúmeras situações, a gestão pública tem sido induzida pela necessidade de responder às demandas por meio de números. A NGP tem recorrido aos números estatísticos para validar as deficiências do serviço público, como forma de atestado da sua ineficiência. Isso tem contribuído para que reformadores empresariais se apropriem desses diagnósticos para vender à administração pública pacotes de soluções, baseados em medidas empresariais, cujo objetivo tem sido construir um senso comum de que o setor público não é tão eficiente quanto a iniciativa privada. Na lógica do setor privado, os resultados 
estatísticos também podem ser utilizados como instrumentos de responsabilização para premiar ou punir organizações do setor público; isso está acontecendo com escolas cuja gestão tem sido orientada por resultados.

A avaliação de desempenho e a publicação de resultados de aprendizagem são dimensões da NGP que têm sido incorporadas pela gestão dos sistemas de ensino como mecanismos para mensurar a qualidade do ensino ofertado nas escolas públicas brasileiras. A lógica dessa concepção gerencial está centrada na gestão por resultados e desempenho das organizações e dos indivíduos (VERGER; NORMAND, 2015).

Apesar de esses dados retratarem, em números, um recorte da realidade, é preciso observá-los com cautela quanto às contribuições destes para o planejamento das políticas educacionais, visto que essa avaliação produz uma política de ranking educacional internacional, o que denota competição entre os países da OCDE visando a alcançar os primeiros lugares dessa escala. Nesse tipo de avaliação, como é o caso do PISA, leva-se em consideração o desempenho cognitivo dos alunos nos testes padronizados e não são avaliados aspectos sociais e econômicos que influenciam esses resultados (AFONSO, 2012).

No Brasil, até o presente momento (2018), não foi aprovada uma LRE, mas é possível extrair algumas lições com o caso norte-americano. Com base na experiência dos Estados Unidos, Freitas (2013) afirma que, em dez anos do PISA, a qualidade da educação naquele país ficou estagnada. Entre as implicações, verificou-se que induziu a criação de um mercado de mais U\$\$ 800 bilhões de dólares, tendo como objetivos oferecer bônus às escolas, ensinar para os testes, privatizar via contratos de gestão (charters school). Essas implicações são características também da política de responsabilização educacional, mais conhecida por No Child Left Behind, que funciona como a lei de responsabilidade educacional norte-americana. Essa lei, além dos seus objetivos, trouxe, como resultados críticos o fechamento de escolas, aplicação de medidas disciplinares radicais, a ponto de demitir professores e gestores com base nos resultados negativos (FREITAS, 2012).

As mediações conceituais identificadas no relatório da Comissão de Educação e Cultura apresentam um forte discurso sustentando a concepção de responsabilidade do Estado no compromisso com a garantia do direito ao acesso à educação de qualidade. Os relatores, Deputado Gilmar Machado (PT-MG) e a Deputada Fátima Bezerra (PT-RN), argumentam que conceituar responsabilidade educacional requer: a) uma clara delimitação da responsabilidade na oferta e garantia da Educação Básica (etapas e modalidades) entre os entes federados e entre o Estado e as famílias; b) o entendimento dos requisitos indispensáveis para 
a educação de qualidade; c) uma definição de parâmetros mínimos de qualidade, em termos de insumos indispensáveis e da responsabilidade dos gestores públicos em assegurar a sua disponibilidade.

Segundo o relatório, são ainda requisitos da responsabilidade educacional: a definição de recursos para promover insumos, a determinação de custos para os parâmetros, a capacidade de atendimento para cada ente federado, e, ainda, a definição de procedimentos e estratégias de cooperação, em termos técnicos e financeiros.

O debate sobre a LRE não se esgota nesse caminho; por esse motivo, a discussão na Câmara dos Deputados ou no Congresso não é o ponto de chegada, mas um ponto de partida cuja trajetória necessita ser retomada para se compreenderem as transformações que podem ocorrer nas políticas educacionais para os próximos anos no país.

\section{DAS CONFERÊNCIAS NACIONAIS DE EDUCAÇÃO AO PLANO NACIONAL DE EDUCAÇÃO (2014-2024): OS CAMINHOS DA RESPONSABILIDADE EDUCACIONAL}

A aprovação do PNE (2014-2024) foi subsidiada por uma série de documentos, entre os quais estão os produzidos pelas Conferências Nacionais de Educação em 2010 e 2014. Mesmo sabendo que o foco sempre foi o PNE, esses documentos materializam uma concepção de responsabilização e da responsabilidade educacional. Porém, antecedendo a aprovação do PNE, é importante observar que, em 18 de março de 2009, Fernando Haddad (ExMinistro da Educação), em reunião com a Comissão de Educação e Cultura, apresentou como uma das prioridades do MEC, para os anos de 2009 e 2010, a criação de mais um instrumento legal, em sua ótica, "mais ativo" para que os gestores observem as metas pactuadas, a fim de garantir o direito ao aprendizado (BRASIL 2009). Para o Ministro daquele período, esse instrumento se refere à aprovação de uma LRE, realçando a necessidade de se criarem mecanismos rígidos de controle das metas relativas à educação.

Dando continuidade a esse percurso, verifica-se que o debate da LRE é colocado na Conae 2010, alinhado com outras dimensões importantes para a reorganização da educação brasileira, objetivando a melhoria dos avanços educacionais, tais como: gestão, financiamento, avaliação, formação, valorização profissional e a necessidade de definição de um sistema nacional de educação (SNE). 
O documento da Conae (2010) reconhece os avanços em termos de ações governamentais para ampliação do direito à educação, de modo particular no que concerne ao financiamento, mas argumenta a necessidade de desenlace de alguns nós críticos, como:

\begin{abstract}
A revisão do papel da União no financiamento da educação básica; a instituição de um verdadeiro regime de colaboração entre os entes federados; o estabelecimento de uma real valorização dos trabalhadores em educação; a definição de referenciais de qualidade para todos os níveis e modalidades de educação/ensino; e a definição do papel da educação superior pública no processo de desenvolvimento do País. [...] Nesse contexto, é fundamental a criação e instituição da Lei de Responsabilidade Educacional [...]. (CONAE, 2010, p. 106)
\end{abstract}

$\mathrm{Na}$ prática, o desatar desses nós configura mais um dos desafios da educação para a próxima década, que consiste não apenas em revisar as responsabilidades federativas, mas os demais "nós" acentuados nesse documento final da Conae 2010. Esse documento destacou que:

Torna-se pertinente a criação de uma lei de responsabilidade educacional que defina meios de controle e obrigue os responsáveis pela gestão e pelo financiamento da educação, nos âmbitos federal, estadual, distrital e municipal, a cumprir o estabelecido nas constituições federal, estaduais, nas leis orgânicas municipais e distrital e na legislação pertinente e estabeleça sanções administrativas, cíveis e penais no caso de descumprimento dos dispositivos legais determinados, deixando claras as competências, os recursos e as responsabilidades de cada ente federado (CONAE, 2010, p. 29).

Nesse sentido, observa-se que há, em princípio, uma visão de responsabilidade educacional materializada em concepção de responsabilização pelo controle da gestão e dos recursos públicos, em caso de não obediência às leis em voga. Essa perspectiva procura disciplinar a gestão e o financiamento da educação, aplicando sanções administrativas, cíveis e penais. Em face dessa complexidade de concepções, é importante que se tenha clareza sobre os impactos da aprovação de uma LRE que aplica mais punições aos gestores públicos, na medida em que são chamados para responder do ponto de vista administrativo, cível e penal pelos processos de organização da educação em suas diferentes etapas da Educação Básica.

Quiçá, a aprovação da LRE não se transforme em mais uma barreira para ampliar o financiamento da educação, assim como acontece com os limites estabelecidos pela Lei de Responsabilidade Fiscal, Lei Complementar $n^{\circ} 101$, de 4 de maio de 2000 (BRASIL, 2005) cuja ferramenta maximiza o controle 
dos recursos públicos deixando gestores públicos, na maioria das vezes, sem alternativas para negociar correções e ajustes salariais dos servidores e outras pautas de lutas desses profissionais.

Esse debate em torno da concepção e aprovação de uma LRE para o Brasil permaneceu concomitante à tramitação e aprovação do Plano Nacional de Educação 2014-2024 no Congresso Nacional. O plano, aprovado pela Lei $\mathrm{n}^{\mathrm{o}}$ 13.005/2014 (BRASIL, 2014), trouxe, em seu anexo, a meta 20, discorrendo sobre a necessidade de "ampliar o investimento público em educação pública de forma a atingir, no mínimo, o patamar de 7\% (sete por cento) do Produto Interno Bruto - PIB do País no 5o (quinto) ano de vigência desta Lei e, no mínimo, o equivalente a $10 \%$ (dez por cento) do PIB ao final do decênio" (BRASIL, 2014). Essa meta é composta de doze estratégias, dentre as quais, a 20.11 diz que, no prazo de 1 (um) ano ${ }^{4}$, a Lei de Responsabilidade Educacional deve ser aprovada, assegurando padrão de qualidade na Educação Básica, em cada sistema e rede de ensino, pelo processo de metas de qualidade aferidas por institutos oficiais de avaliação educacionais ${ }^{5}$.

Esse debate sobre a necessidade de uma LRE aparece fortemente na agenda da Conae de 2014. Embora tenha sido realizada após a aprovação do PNE 2014-2024, seu documento-referência alude à necessidade de criação e implementação do Sistema Nacional de Educação, assim como a regulamentação do regime de colaboração. Como parte do fortalecimento desse processo de implantação de uma política de Estado, verifica-se que esse documento reforçou, no Eixo I, sobre "o Plano Nacional de Educação e do Sistema Nacional de Educação: organização e regulação”, a prerrogativa de que

Aliado a esse processo, deve-se criar uma lei de responsabilidade educacional que
defina meios de controle e obrigue os responsáveis pela gestão e pelo financiamento
da educação, nos âmbitos federal, estadual, distrital e municipal, a cumprir o
estabelecido nas constituições federal, estaduais, nas leis orgânicas municipais e
distrital e na legislação pertinente e estabeleça sanções administrativas, cíveis e
penais no caso de descumprimento dos dispositivos legais determinados, deixando
claras as competências, os recursos e as responsabilidades de cada ente federado. (FNE, 2013, p. 21)

$4 \quad$ O prazo já está expirado e, desde o golpe sofrido pela presidente Dilma Roussef em agosto de 2016, o futuro da LRE ficou incerto, inclusive a aprovação do relatório final da Comissão Especial ficou cada vez mais distante.

5 Esse prazo já se esgotou, e continuam os embates em torno da definição da LRE no Congresso Nacional. 
Conforme observado, esse documento atribui à União a responsabilidade em face do conjunto dos sistemas de ensino. Nessa concepção, o referido documento reforça a LRE como estratégia para consolidar o PNE e o SNE como política de Estado, conforme proposição contida na estratégia 15 do Eixo 1: "Instituir Lei de Responsabilidade Educacional (LRE), no prazo previsto pelo PNE, pautada pela garantia de educação democrática e de qualidade como direito social inalienável" (FNE, 2013, p. 22).

De acordo com Freitas (2011, s/p),

A ideia de que a qualidade da educação possa ser controlada por uma lei já indica uma certa inclinação para o mote da "qualidade por decreto". Pode-se responsabilizar os gestores pela gerência de recursos e condições adequadas à implementação da qualidade, mas a lei dificilmente vai parar por aí.

Nessa direção, a responsabilização adquire um caráter autoritário que prioriza a lógica do controle de resultados. A lógica do controle, enquanto método gerencial, não é inédita, e ainda consiste em uma das medidas organizativas e administrativas da nova gestão pública.

Nesses termos, considera-se que avaliação, responsabilização, controle e divulgação dos resultados definem alguns contornos da Nova Gestão Pública em educação, que objetiva, de algum modo, implantar processos balizados na gestão profissional no setor público; no estabelecimento de padrões e medidas de desempenho explícitas; na ênfase no controle de resultados; na divisão do setor público em unidades menores; nos níveis mais elevados de competência; na ênfase no estilo de gestão do setor público com base no modelo do setor privado; na disciplina e avaliação dos recursos (HOOD, 1995; GRUENING, 2001).

Desse modo, por um lado, a proposição de uma LRE no Brasil está localizada no quadro da NGP, que se configura como uma ferramenta gerencial para reforçar o controle sistemático do desempenho dos sistemas educacionais e das redes de escolas públicas. Por outro lado, pode contribuir para melhorar a gestão desses sistemas e redes, introduzindo a modernização dos processos gestionários.

\section{O TRÂNSITO DOS PROJETOS DE LEI DE RESPONSABILIDADE EDUCACIONAL NA CÂMARA DOS DEPUTADOS (2006-2015)}

Nesta parte do artigo, foram considerados os diversos Projetos de Lei que deram entrada e tramitam na Câmara dos Deputados. Para sua leitura, adotaram-se os seguintes passos: levantamento, no site da câmara, dos projetos de leis que se reportam à concepção de uma LRE; em seguida, procedeu-se a 
uma leitura flutuante das ementas das proposições para construção de unidades de registro e de sentido; e finalizou com a elaboração de inferências sobre os PLs que ora destacam aproximações ora contradições em torno do surgimento e das concepções, necessárias à construção de uma LRE.

No período 2006 a 2015, foram localizados no sítio da Câmara dos Deputados 21 projetos relacionados ao tema da Lei de Responsabilidade Educacional. No quadro geral, observa-se que, no ano de 2006, foi proposto, apenas, um Projeto de Lei ( $n^{\circ}$ 7.420), de autoria da Deputada Raquel Teixeira, do PSDB de Goiás. No ano de 2007, foram apresentados quatro projetos, assim distribuídos: Projeto n ${ }^{\circ} 247$, de autoria do Deputado Sandes Júnior, do PP de Goiás; Projeto $n^{\circ}$ 600, de autoria do Deputado Carlos Abicalil, do PT de Mato Grosso; Projeto n ${ }^{\circ}$ 1.256, de autoria do Deputado Marcos Monte, do DEM de Minas Gerais; Projeto no 1.680, de autoria do Deputado Lelo Coimbra, do PMDB do Espírito Santo.

No ano de 2009, foi apresentado, apenas, um projeto (4.889) de autoria do Deputado Lincoln Portela, do PR de Minas Gerais. No ano de 2010, foram apresentados dois projetos, sendo um de autoria do Poder executivo ( $\mathrm{n}^{\circ}$ 8.039) e outro do Deputado Jovair Arantes (n 042), do PTB de Goiás. No ano de 2011, foram apresentados sete projetos, assim distribuídos: Projeto $n^{\circ} 413$ de autoria do Deputado Gastão Vieira, do PMDB do Maranhão; Projeto n ${ }^{\circ} 450$ de autoria do Deputado Tiago Peixoto, do PMDB de Goiás; Projeto no 1.747 de autoria da Deputada Teresa Surita, do PP de Roraima; Projeto no 1.915 de autoria do Deputado Carlos Souza, do PP do Amazonas; Projeto no 2.417 (sem autoria identificada); Projeto $n^{\circ}$ 2.604, de autoria do Deputado Tiago Peixoto, do PMDB de Goiás; Projeto no 3.066, de autoria do Deputado Romero Rodrigues, do PSDB da Paraíba.

No ano de 2013, foram protocolados quatro projetos, assim especificados: Projeto n ${ }^{\circ}$ 5.519, do Deputado Paulo Ruben Santiago, do PDT de Pernambuco; Projeto $n^{\circ}$ 5.647, da Deputada Rosane Ferreira, do PV do Paraná; Projeto $n^{\circ}$ 5.907 (não localizado); Projeto no 6.137, da Deputada Keiko Ota, do PSB de São Paulo. No ano de 2015, foram protocolados dois Projetos, sendo um, de $\mathrm{n}^{\circ}$ 51, de autoria da Deputada Carmem Zanotto, do PPS de Santa Catarina e o outro, de $\mathrm{n}^{\circ}$ 89, de autoria do Deputado Adail Carneiro, do PHS do Ceará.

Identificados todos os projetos, foi realizada uma leitura e síntese das ementas, para sintetizar o conteúdo das propostas neles contidas. Embora se reconheçam limitações na realização de uma leitura exploratória das ementas desses projetos, é importante destacar que esse passo foi relevante para a apropriação de uma ideia inicial, mas não determinante sobre o sentido do conteúdo proposto. 
Evidencia-se que o conteúdo dos projetos apresenta especificidades e aproximações em relação ao entendimento de seus propositores sobre responsabilidade educacional. Nesse sentido, em observância ao conteúdo desses PLs, é possível identificar uma série de concepções de responsabilidade educacional que relacionam ou condicionam a qualidade da educação a dimensões do financiamento da educação, com possibilidade de restrição de repasse de recursos para aqueles gestores públicos que não conseguirem responder, positivamente, pelos resultados do ente representado. Além disso, alguns deles inserem proposições de alterações na LDB 9.394/1996, no tocante à definição de padrão mínimo de qualidade da educação. Convém, ainda, destacar que uma série de questões jurídicas é evocada para acionar a responsabilidade do gestor público, que, por omissão ou improbidade administrativa, deixar de atender, com qualidade, aos cidadãos nos serviços educacionais.

Em face dessa leitura, foi possível elaborar o quadro 1, que procura reunir os projetos de leis com base nas aproximações temáticas. Esse quadro apresenta uma síntese dos conteúdos dos projetos de leis apensados ao projeto principal, definindo alguns encaminhamentos para a elaboração de um substitutivo proposto pela Câmara dos Deputados, pelo Deputado Bacelar ${ }^{6}$, novo relator da Comissão Especial.

\section{QUADRO 1 - Distribuição dos Projetos de Lei, segundo aproximação de temáticas}

\begin{tabular}{|c|c|c|}
\hline Codificação & Projetos de Lei & Síntese dos conteúdos \\
\hline 01 & $\begin{array}{c}\text { n. } 1.680 / 2007 \\
\text { n. } 413 / 2011 \\
\text { n. } 450 / 2011\end{array}$ & $\begin{array}{c}\text { O mesmo teor do projeto principal 7.420/06; apresenta padrões de } \\
\text { oferta da educação de qualidade. }\end{array}$ \\
\hline 02 & $\begin{array}{l}\text { n. } 1.747 / 2011 \\
\text { n. } 2.604 / 2011 \\
\text { n. } 1.915 / 2011 \\
\text { n. } 3.066 / 2011\end{array}$ & Avaliação do rendimento escolar na educação básica. \\
\hline 03 & n. $4.866 / 2009$ & $\begin{array}{l}\text { Padrões mínimos, custo/padrão/qualidade e da ação supletiva e } \\
\text { redistributiva da União. }\end{array}$ \\
\hline 04 & $\begin{array}{c}.247 / 2007 \\
\text { n. } 660 / 2007 \\
\text { n. } 1.256 / 2007 \\
\text { n. } 8.042 / 2006\end{array}$ & $\begin{array}{l}\text { Penalizações de agentes públicos, de pais ou responsáveis pelos } \\
\text { resultados. }\end{array}$ \\
\hline
\end{tabular}




\section{QUADRO 1 - Distribuição dos Projetos de Lei, segundo aproximação de temáticas}

\begin{tabular}{|c|c|c|}
\hline Codificação & Projetos de Lei & Síntese dos conteúdos \\
\hline 05 & $\begin{array}{c}\text { n. } 5.647 / 2013 \\
\text { n. } 6.137 / 2013\end{array}$ & $\begin{array}{r}\text { Responsabilidades de comunicação das escolas sobre faltas e } \\
\text { riscos de evasão escolar dos alunos. }\end{array}$ \\
\hline 06 & n. $8.039 / 2010$ & Ação civil pública. \\
\hline 07 & n. $2.417 / 2011$ & Arranjos de desenvolvimento da educação. \\
\hline 08 & n. $5.519 / 2013$ & Sistema Nacional de Educação. \\
\hline 09 & n. $5.907 / 2013$ & Obrigações de oferta de Educação de Jovens Adultos. \\
\hline
\end{tabular}

Fonte: Elaborado com base no Relatório da Comissão Especial de Educação (BRASIL, 2013a).

Com base na síntese apresentada no quadro1, verifica-se que a construção da LRE requer definições claras sobre esse tema, com destaque para o papel dos agentes envolvidos e para os parâmetros de qualidade para os sistemas de ensino. Com isso, não se deve esquecer de que uma nova base precisa ser organizada, assim como revisitar alguns pontos da legislação vigente para que se possa chegar a uma concepção de responsabilidade pela qualidade da oferta educacional; isso é o que sinaliza a síntese dos conteúdos dos projetos que tramitam na Câmara dos Deputados.

Ao consultar as informações registradas nos relatórios da Comissão de Finanças e Tributação (2009), da Câmara dos Deputados, elaborado pelo relator Deputado Geraldino dos Santos (PSOL-RS), fica evidente que há uma diversidade de preocupações e entendimentos sobre o que significa "Responsabilidade Educacional", bem como sobre a necessidade de se explicar qual o conceito de qualidade a ser defendido.

Esse fato pode ter sido determinante para que a Câmara dos Deputados tenha decidido reunir os PL's para deliberação conjunta, tendo, como referência, o PL n ${ }^{\circ} 7420 / 2006$.

Para Ximenes (2012), o amplo escopo de projetos e as disputas de diferentes concepções de responsabilidade educacional trouxeram como consequência a necessidade da ampliação do enfoque do debate sobre esse tema, em que responsabilidade e qualidade foram colocadas como agendas de juridificação do direito à educação e a sua qualidade.

Além desse processo de debate nas comissões da Câmara dos Deputados, o PL n ${ }^{\circ} 7.420 / 2006$ passou por uma série de audiências públicas, consideradas espaço do efetivo debate sobre a construção de uma política, econômica, ou social. Nesse sentido, houve inúmeras audiências (embora no sítio da Câmara apareçam somente quatro), contando com a participação de diversos segmentos 
da sociedade e do Poder Executivo ${ }^{7}$. Essas audiências contribuem para a viabilização do diálogo plural, ora revelando posturas em defesa da Política de Responsabilidade Educacional, ora apresentando posturas contrárias à concepção de responsabilidade presentes no PL e nos demais projetos a ele apensados.

Destaca-se que se observou, em uma dessas audiências públicas ${ }^{8}$, a participação de representações de Associações Científicas que fizeram ressalvas à LRE no país. Tais reflexões foram de suma importância para se debaterem as expectativas e as tensões relativas a esse tema e para situar a educação como foco da agenda nacional, possibilitando, ao mesmo tempo, uma visão mais acadêmica no debate sobre essa temática. Na audiência realizada em 5 de junho de 2013, os professores e pesquisadores, Dr. João Ferreira de Oliveira (à época, vicepresidente da Anped) e a Dra. Gilda Cardoso de Araújo (CEDES), estiveram presentes.

Nessa audiência, o Professor Dr. João Ferreira de Oliveira abordou o debate sobre uma agenda educacional ampla e complexa que vem se instituindo no Brasil, com mais evidências, desde a Constituição Federal (BRASIL,1988), culminando com a Conferência Nacional de Educação (Conae) realizada em 2010. Esses processos influenciaram na discussão e no aperfeiçoamento do PNE (20142024), inserindo o debate sobre a possibilidade de uma Lei de Responsabilidade Educacional (OLIVEIRA, 2013).

Nesse contexto, Oliveira (2013) argumenta que uma LRE poderia auxiliar na garantia de uma educação de qualidade para todos, mas não se exime de considerar que há riscos, em função da pluralidade de sistemas. Propõe que se não houver a constituição da articulação e da colaboração, o Executivo continuará implantando políticas no âmbito da União, dos estados e dos municípios sem a ressonância daquilo que realmente se deseja, ou seja, um processo de ensinoaprendizagem de qualidade.

A Professora Doutora Gilda Cardoso de Araújo, representante do Cedes, foi mais contundente em relação à análise do tema (ARAÚJO, 2013). Assinala a autora que, diante dos vários projetos de lei, há um campo de disputas que corre o

\footnotetext{
Com base em informações do sítio da Câmara dos Deputados, essas audiências contaram com a participação de várias representações, tais como: Binho Marques (SASE), Rossielle Soares da Silva (Secretária de Educação e da Qualidade do Ensino do Amazonas), Alessio Costa Lima (União dos Dirigentes Municipais de Ensino), Mariza Abreu (Consultora na Área de Educação da Conferência Nacional de Municípios), Raul Henry (Vice-governador do Estado do Pernambuco e ex-relator do PL na 54 legislatura), Alípio dos Santos Neto (Diretor de Fiscalização da Educação e Cultura no Tribunal de Contas da União) e Francisco Soares (Presidente do INEP).

8 O vídeo sobre a audiência pública de 05 de junho de 2013 se encontra publicado em: <https:// www.youtube.com $/$ watch?v=j7kkPAUDH0M $>$.

9 A professora Gilda Cardoso de Araújo substituiu a professora Ivani Pino em decorrência de problemas de saúde, por esse motivo, a referida professora compareceu a essa audiência.
} 
risco de responsabilizar a totalidade dos agentes públicos, incluindo os docentes, por ato de improbidade administrativa em razão do não cumprimento de metas de avaliação.

A análise efetivada por Araújo (2013) sobre os projetos que se encontram na Câmara dos Deputados conclui que as concepções em disputa são as que buscam uma definição de custo/aluno/qualidade que não pode limitar-se à definição dos insumos, mas dos processos e dos resultados, tendo esse tripé como base da qualidade. A outra disputa, mencionada pela autora, é a que se dá entre o direito à educação e as expectativas de direito à aprendizagem; sendo que essa última expressão tem a ver com o individualismo, com ênfase nos resultados. Isso significa que um direito público é tomado como direito privado do consumidor de produtos educacionais. E é inconcebível que isso ocorra com a educação brasileira.

Cabe destacar que essa perspectiva da responsabilização pela meritocracia, pelos testes em larga escala, provocou um estreitamento curricular, cuja defesa é a de que o teste é bom porque se "cobra" o básico do aluno; desse modo, se isso é cobrado como bom e básico, é bom para todo mundo, configurando um discurso tautológico. Entretanto, faz-se necessária uma educação que ofereça mais do que básico, para que o Brasil alcance seu desenvolvimento pleno.

Nesse debate sobre a LRE não pode ficar de fora uma referência ao regime de colaboração. A regulamentação do regime de colaboração somente será possível se, nesse processo, for considerado quem será responsabilizado, o que significa a existência de concorrência e a função supletiva de cada ente federado. Do ponto de vista da federação, responsabilidade requer relação direta com atribuição de competência, não havendo, portanto, como dissociar o debate sobre responsabilidade educacional do debate do regime de colaboração (ARAÚJO, 2013).

A participação da Secretaria de Articulação com os Sistemas de Ensino (Sase) também é importante nesse processo, pois defendeu que a aprovação da LRE não deveria preceder um Sistema Nacional de Educação ${ }^{10}$; propõe um projeto de

10 Em nota publicada no dia 24 de novembro de 2015, o FNE solicitou à Comissão Especial da Câmara dos Deputados a suspensão da tramitação da matéria, até ser elaborado pelo Poder Executivo o projeto de Lei acerca do Sistema Nacional de Educação, do Custo Aluno-Qualidade inicial (CAQi), do Custo Aluno Qualidade (CAQ) e dos regimes de cooperação e colaboração interfederativas (FNE, 2015). Para o FNE (2015), a LRE possui competência de controle de políticas públicas educacionais, não cabendo definir os critérios de qualidade da educação, pois esse tema compete às leis que regulamentarão o SNE, tais como CAQi, CAQ e Gestão Democrática. Nessa ótica, é preciso não se contrapor à ordem natural do processo de regulamentação do SNE. Nesse aspecto, o FNE discorda da ideia de que uma LRE possa definir padrões de qualidade, pois a função dessa lei deve ser a fiscalização das leis anteriores. Percebe-se que o entendimento do FNE caminha próximo do que pensam as entidades cientificas, o CEDES e a ANPAE, que vislumbram, principalmente, a criação do SNE e as regulamentações decorrentes (FNE, 2015). 
responsabilidade educacional que envolve três dimensões da qualidade: presença de insumos, processos de gestão administrativa, normativa e pedagógica, além de uma concepção de qualidade vinculada à realização dos objetivos educacionais.

A posição da Sase referente à aprovação de uma LRE é contrária à concepção de uma política de responsabilidade educacional que torna a lei instrumento de punição, conforme se observa:

\begin{abstract}
Sempre fomos contrários à punição pelo não atingimento de metas de desempenho dos estudantes, posicionamento marcado pelo MEC, desde 2010, com o PL 8.039/2010, do Executivo. [...] responsabilizar, na agenda constituinte do SNE, deve ser além da definição de responsabilidades, a previsão das condições para o seu exercício e para o seu acompanhamento e controle. [...] quem faz o que [...] com quem e em que condições faz, com quais mediações de complementaridades, com quais regramentos e com quais redefinições de responsáveis pelas deliberações (BRASIL, 2016, p. 9).
\end{abstract}

Com base nesse argumento, a Sase se revela oposta a uma perspectiva de responsabilização que prevê aplicação de punições atreladas ao desempenho, pois entende que o conceito de responsabilização não deve estar limitado à concepção de penalizações, mas imbuído de responsabilidades definidas, previsão de acompanhamento e condições para que os sistemas educacionais possam alcançar bons resultados. Nesse sentido, é possível inferir que essa concepção se aproxima, sobretudo, de uma política ideal de democratização das relações entre Estado e sociedade, presumindo a definição dos responsáveis e as regras necessárias no processo deliberativo.

Assim, uma concepção de responsabilidade educacional não deve desvincular-se, também, de uma noção de qualidade, que, para a Sase (2016), pode ser entendida como processo permanente de aprimoramento administrativo, normativo e pedagógico. A qualidade se concretiza, para esse órgão, quando os indicadores de desigualdade são considerados, é efetivada a inclusão de grupos historicamente marginalizados e estruturas de controle social que coletam e sistematizam informações sobre cada rede de ensino concernente "ao progresso de metas, estratégias, ações, programas, e projetos implementados no âmbito dos planos decenais de educação aprovados em lei” (BRASIL, 2016, p. 6).

No tocante à responsabilização, a proposta da Sase (BRASIL, 2016) vincula a implantação do CAQ e os mecanismos de controle e do Sistema Nacional conforme metas previstas no PNE (2014-2024), definindo o apoio supletivo da União e a responsabilização do dirigente pelo padrão básico de oferta. A Sase, por meio de seus representantes, entende que os mecanismos de responsabilização 
não elidem sanções aplicáveis aos agentes públicos nos casos de enriquecimento ilícito, da ação civil pública de responsabilidade por danos causados e crimes de responsabilidade.

Para a Sase, responsabilidade educacional significa, no discurso registrado em documento, a definição de meios de controle e estabelecimento de referenciais e mecanismos para exigir o cumprimento de obrigações legais na área da educação.

A responsabilização dos gestores e o protagonismo dos segmentos escolares, nos processos de tomadas de decisão das organizações educativas, estão presentes na introdução da nova gestão pública na educação. Esse modelo gerencial vai sendo delineado, construindo o argumento de que se consubstancia em uma resposta aos desafios de melhorias da eficiência e eficácia dos sistemas educativos públicos. Nesse sentido, para viabilizar um novo paradigma de gestão pública, vários instrumentos foram colocados à disposição desse novo modelo (SOUZA, 2016).

\section{CONCLUSÕES}

A concepção de uma LRE no Brasil faz um percurso de promessas e incertezas em relação à qualidade do ensino ofertado nos sistemas e nas redes de escolas públicas. Evidentemente, não será por força de uma lei que os problemas educacionais serão resolvidos, pois, ao se considerar o histórico da legislação educacional brasileira, será possível perceber que há um aparato jurídico construído que regula o direito à educação do ponto de vista do acesso, permanência e a aprendizagem, característico de um processo em que a qualidade é referenciada por meio de decreto. Reconhece-se, no entanto, sua importância enquanto dispositivo regulador para seu aprimoramento.

$\mathrm{Na}$ concepção daqueles que participaram dos debates e que fizeram proposições no âmbito da Câmara dos Deputados para conceber um Projeto de Lei de Responsabilidade Educacional, e que idealizam, até certo ponto, uma visão da melhoria da qualidade da educação, observa-se que há distanciamentos e aproximações nesse campo de disputa. A proximidade está presente quando se considera importante defender o direito à educação de qualidade e à sua oferta. Por outro lado, complexificam essa relação entre qualidade e financiamento da educação, impondo restrições financeiras aos entes federados que não conseguirem melhorar seus resultados a cada ano. Com isso, a lógica da NGP se coloca enquanto diretriz da responsabilização pelo controle de resultados e da competição administrada. Entretanto, a aprovação de uma LRE não deve preceder a aprovação do Sistema Nacional de Educação, tampouco a regulamentação do regime de colaboração. 
O conteúdo dos PLs revela posicionamentos que se colocam como referência para a concepção de uma LRE, em que a relação da responsabilidade educacional se complexifica com outras óticas, tais como: a garantia do direito à educação e a qualidade, o financiamento e a implantação de estratégias de responsabilização. No entanto, a problematização dessas complexidades não é garantia de que venham a materializar-se na aprovação de um texto final para a LRE, pois, além das divergências conceituais frente às noções de responsabilidade e responsabilização construídas no interior desse debate, há PLs que apresentam uma visão menos radical quanto ao conteúdo proposto no projeto original $\left(\mathrm{n}^{\circ}\right.$ 7.420/2006) que prevê penalidades graves aos secretários de educação, diretores de escolas, professores e pais. A redação final ainda pode sofrer influência do contexto político e econômico, baseada nos interesses daqueles que estiverem de plantão.

Portanto, os projetos de leis apensados à proposta original da Deputada Raquel Teixeira corroboram as diferenças tanto na concepção de responsabilidade educacional quanto nos objetivos de qualidade educacional. $\mathrm{O}$ debate se torna mais complexo quando as propostas do legislativo vinculam resultados escolares ao financiamento da educação.

Avalia-se que essa proposta é um composto da "fórmula mais do mesmo", visto que reúne, em uma lei, obrigações jurídicas que já estavam definidas na legislação brasileira e as possíveis sanções àqueles indivíduos representantes da gestão pública que não conseguem realizar um conduta ilibada, podendo ser julgados por crime de responsabilidade, nos moldes do código civil, da obediência ao Estatuto da Criança e do Adolescente, e nos limites da Lei de Responsabilidade Fiscal. A suspensão de recursos públicos pode induzir mais ainda a perda de qualidade dos sistemas. Além desses fatores, é incompatível com uma sociedade construída com base nos valores democráticos. Por esse motivo, avançar sem recursos é praticamente impossível e compromete cada vez mais a qualidade do ensino.

A previsão de suspensão temporária de recursos é uma punição severa para as escolas, uma vez que são consideradas as menores unidades do sistema; além disso, comportam maior número de cidadãos que utilizam seus serviços. A suspensão do financiamento devido aos resultados escolares pode transformarse em uma estratégia de aprofundamento do fracasso da escola. Entretanto, o uso dos seus recursos deve ser fiscalizado para que se saiba como estão sendo administrados e se estão compatíveis com as condições em que o ensino é ofertado. Nessa perspectiva, a restrição de financiamento significa um instrumento a mais de punição. 
Não obstante, é possível desenhar algumas alternativas para que esses problemas sejam enfrentados e que podem ser encontradas: a) na melhoria da gestão, aperfeiçoando-se as estratégias de seleção dos profissionais responsáveis pela escola (diretores, coordenadores, professores e técnicos educacionais); b) na valorização do trabalho do professor; c) na concepção, implementação e avaliação dos projetos político-pedagógicos; d) na reestruturação democrática dos espaços de participação, como conselhos escolares, grêmios estudantis, associações de pais e educadores; e) na organização de um regime de colaboração mais transparente, capaz de reduzir as diferenças financeiras entre os entes federados, objetivando alcançar maiores patamares de igualdade política, econômica e social no país, para corrigir as injustiças sociais, a distribuição de renda e, assim, conseguir a emancipação dos indivíduos.

Uma particularidade que deve ser observada é que uma LRE de cunho nacional também enfrenta tensões derivadas de suas limitações à realização de uma educação pública de qualidade e não poderá considerar apenas metas de desempenho aferidas por exames nacionais.

Quiçá, esse movimento de construção da LRE no Brasil não se transforme em mais uma lei aprovada que opera com dificuldades para ser implementada, como mais uma lei morta. Não é admissível a previsão de punições que atentem apenas para a ponta do sistema, desembocando em suas unidades menores, as escolas.

\section{REFERÊNCIAS}

AFONSO, Almerindo J. Para uma concepção alternativa de accountability em educação. Educação e Sociedade, Campinas, v. 33, n. 119, abr./jun. 2012. Disponível em: <http://www.scielo.br/scielo.php?script=sci_arttext\&pid =S0101-73302012000200008> . Acesso em: 11 maio 2016 .

ARAÚJO, Gilda Cardoso de. Comissão Especial Projeto de Lei no 7420, de 2006. Audiência Pública. 05 de Junho de 2013. Disponível em: https://www.youtube. com/watch?v=j7kkPAUDH0M. Acesso em: 20 de dezembro de 2015.

ARAÚJO, Maria Arlete D. Responsabilização pelo controle de resultados no Sistema Único de Saúde no Brasil. Revista Panam Salud Publica, Washington, n. 27 , v. 3, p. 230-236, 2010.

BARDIN, Laurence. Análise de conteúdo. São Paulo: Edições 70, 1977. 
BRASIL. MEC. Secretaria de Articulação com os Sistemas de Ensino (SASE). Documento interno: circulação restrita. Brasília, 25 de fevereiro de 2016.

Lei n. 13.005 de 24 de junho de 2014. Aprova o Plano Nacional de Educação-PNE e dá outras providências. Brasília, 2014.

. Câmara dos Deputados. Comissão Especial de Educação. Relatório. Brasília. 2013.

BRASIL. Projeto de Lei N. ${ }^{\mathbf{7}}$ 7.420, de 2006 (da Senhora Professora Raquel Teixeira). Dispõe sobre a qualidade da educação básica e a responsabilidade dos gestores públicos na sua promoção. Brasília: Câmara dos Deputados, 2013b. Disponível em: https://www.camara.gov.br/proposicoesWeb/prop_mostrarint egra?codteor $=1065736 \&$ filename $=$ Avulso + -PL $+7420 / 2006$. Acesso em: 26 de julho de 2017.

Câmara dos Deputados. Comissão de Finanças e Tributação. Relatório. Brasília. Projeto de Lei $\mathrm{n}^{\mathrm{o}} 7.420 / 2006$ (apensados P.Ls. $\mathrm{n}^{\mathrm{o}} \mathrm{s} 1.680$, de 2007, e 4.886, de 2009). Brasília, 2010.

Ministério da Educação. Comissão de Educação da Câmara. 2009. Disponível em: http://portal.mec.gov.br/component/tags/tag/32919-leiresponsabilidade-educacional

Câmara dos Deputados. Comissão de Educação e Cultura. Relatório. Projeto de Lei 7.420/2006. Brasília, 02 de maio de 2007.

Lei de Responsabilidade Fiscal (2000). Lei de responsabilidade fiscal: lei complementar n.101, de 4 de maio de 2000. 4. reimp. Brasillia: Senado Federal, Subsecretaria de Edições Técnicas, 2005.

. Constituição da República Federativa do Brasil. Brasília: Senado Federal. 1988.

CONAE. Conferência Nacional de Educação: documento-referência. Fórum Nacional de Educação. Brasilia: Ministério da Educação, 2010. 
FNE. Fórum Nacional de Educação. $33^{\mathrm{a}}$ nota pública do Fórum Nacional de Educação: pela suspensão da tramitação do PL 7.420/2006, que trata da Lei de Responsabilidade Educacional. Brasília, 24 de novembro de 2015.

Conferência Nacional de Educação: documento-referência. Brasília: Ministério da Educação, 2013.

FREITAS, Luiz C. Políticas de responsabilização: entre a falta de evidência e a ética. Cadernos de Pesquisa, São Paulo, v.43, n.148, p.348-365, jan./abr. 2013.

.Os reformadores empresariais da educação: da desmoralização do magistério à destruição do sistema público de educação. Educação e Sociedade, vol.33, n.119, pp.379-404, 2012. Disponível em:<http://dx.doi.org/10.1590/ S0101-73302012000200004>. Acesso em: 15 de dezembro de 2016.

. Lei de Responsabilidade Educacional? Revista Eletrônica de Jornalismo Científico, 10 de Outubro de 2011. Disponível em: <http://www.comciencia. $\mathrm{br} /$ comciencia $/$ handler.php?section $=8 \&$ edicao $=71 \& \mathrm{id}=889 \& \mathrm{tipo}=1 \& \mathrm{print}=\mathrm{tr}$ ue>. Acesso em: 22 de dezembro de 2015.

GRUENING, Gernod. Origin and theoretical basis of New Public Management. International Public Management Journal, United Kingdom, n. 4, p. 1-25, 2001.

HOOD, Cristopher. The "new public management" in the 1980s: variations on a theme. Accounting, Organizations and Society, v. 20, n. 3, p. 93-109, 1995.

O'DONNEL, Guillermo. Accountability horizontal e novas poliarquias. Lua Nova, São Paulo, n.44, 1998. Disponível em: http://www.scielo.br/scielo. php?script $=$ sci_arttext\&pid=S0102-64451998000200003 Acesso em: 10 de dezembro de 2015.

OLIVEIRA, João Ferreira. Comissão Especial Projeto de Lei n ${ }^{\mathbf{7}}$ 7420, de 2006. Audiência Pública. 05 de Junho de 2013. Disponível em: https://www.youtube. com/watch?v=j7kkPAUDH0M. Acesso em: 20 de dezembro de 2015.

OLIVEIRA, Romualdo; ARAÚJO, Gilda. Qualidade do Ensino: uma nova dimensão do direito à educação. Revista Brasileira de Educação, Rio de Janeiro, n. 28, jan.-abr. 2005. 
SINTEGO. Responsabilidade Educacional. Programa Opinião. TV Assembleia. Exibido em 02 de setembro de 2013. Disponível em: <https:/ /www. youtube.com/watch?v=YNsvYIVob7Y>. Acesso em: 22 de dezembro de 2014.

\section{SOUZA, Allan Solano. Responsabilização na Administração da Educação:}

a política de responsabilidade educacional como engrenagem de controle de resultados. 2016. 306 f. Tese (Doutorado em Educação). Universidade Federal do Rio Grande do Norte, Natal, 2016.

VERGER, Antoni; NORMAND, Romuald. Nueva gestión pública e educación: elementos teóricos y conceptuales para el estúdio de un modelo de reforma educativa global. Educação e Sociedade, Campinas, v. 36, n. 132, p. 573-840, jul./set. 2015.

XIMENES, Salomão. Responsabilidade Educacional: concepções diferentes e riscos iminentes ao direito à educação. Educação e Sociedade, Campinas, v. 33, n. 119 , p. 353-377, abr./jun. 2012.

ALLAN SOLANO SOUZA é Doutor em Educação pela Universidade Federal do Rio Grande do Norte (UFRN). Professor Adjunto IV, da Universidade do Estado do Rio Grande do Norte (UERN), lotado no Departamento de Educação. É docente permanente do Programa de Pós-Graduação em Educação da UERN, desenvolvendo estudos na linha "Políticas e Gestão da Educação". E-mail: asolanosouza@gmail.com

ANTÔNIO CABRAL NETO é Doutor em Educação pela Universidade de São Paulo (USP). Professor Titular do Centro de Educação CE, da Universidade Federal do Rio Grande do Norte (CE/UFRN). É docente permanente do Programa de Pós-Graduação em Educação (PPGEd), desenvolvendo estudos e pesquisas na linha “Educação, Política e Práxis Educativas”. E-mail: acabraln@yahoo.com.br 